Louisiana State University

LSU Digital Commons

Faculty Publications

Department of Chemistry

7-1-2018

\title{
Stabilization of miscible viscous fingering by a step growth polymerization reaction
}

\author{
S. Stewart \\ William Jewell College \\ D. Marin \\ William Jewell College \\ M. Tullier \\ Louisiana State University \\ J. Pojman \\ Louisiana State University \\ E. Meiburg \\ University of California, Santa Barbara
}

See next page for additional authors

Follow this and additional works at: https://digitalcommons.Isu.edu/chemistry_pubs

\section{Recommended Citation}

Stewart, S., Marin, D., Tullier, M., Pojman, J., Meiburg, E., \& Bunton, P. (2018). Stabilization of miscible viscous fingering by a step growth polymerization reaction. Experiments in Fluids, 59 (7) https://doi.org/ $10.1007 / \mathrm{s} 00348-018-2566-4$

This Article is brought to you for free and open access by the Department of Chemistry at LSU Digital Commons. It has been accepted for inclusion in Faculty Publications by an authorized administrator of LSU Digital Commons.

For more information, please contact ir@lsu.edu. 


\section{Authors}

S. Stewart, D. Marin, M. Tullier, J. Pojman, E. Meiburg, and P. Bunton 


\section{UC Santa Barbara}

\section{UC Santa Barbara Previously Published Works}

\section{Title}

Stabilization of miscible viscous fingering by a step growth polymerization reaction

Permalink

https://escholarship.org/uc/item/3h6518v5

\section{Journal}

Experiments in Fluids, 59(7)

ISSN

0723-4864

\section{Authors}

Stewart, S

Marin, D

Tullier, $\mathrm{M}$

et al.

Publication Date

2018-07-01

\section{DOI}

10.1007/s00348-018-2566-4

Peer reviewed 


\title{
Stabilization of miscible viscous fingering by a step growth polymerization reaction
}

\author{
S. Stewart ${ }^{1}$, D. Marin ${ }^{1}$, M. Tullier ${ }^{2}$, J. Pojman², E. Meiburg ${ }^{3}$ and P. Bunton ${ }^{1}$ \\ ${ }^{1}$ Department of Physics and Mathematics, William Jewell College, Liberty, Missouri \\ 64068, USA \\ ${ }^{2}$ Department of Chemistry, Louisiana State University, Baton Rouge, Louisiana \\ 70803, USA \\ ${ }^{3}$ Department of Mechanical Engineering, University of California at Santa Barbara, \\ Santa Barbara, CA 93106, USA
}

\begin{abstract}
Fingering is a hydrodynamic instability that occurs when a more mobile fluid displaces a fluid of lower mobility. When the primary source of the mobility difference is viscosity, the instability is termed viscous fingering. Viscous fingering is often, though not always, undesirable in industrial processes, particularly secondary petroleum recovery. Linear stability analysis by Hejazi et al. has indicated that the production of a non-monotonic viscosity profile can stabilize the interface. Herein, we use step-growth polymerization at the interface between two miscible monomers as a model system. In particular a dithiol monomer displaced a diacrylate that reacted to form a linear polymer that behaves as a Newtonian fluid. Viscous fingering was imaged in a horizontal Hele-Shaw cell via Schlieren, which is sensitive to changes in index of refraction and therefore polymer conversion. By varying reaction rate via initiator concentration along with flow rate via a syringe pump, we were able to demonstrate increasing stabilization of the flow with increasing Damköhler number.
\end{abstract}

\section{Introduction}

Viscous fingering (VF) refers to a fluid instability when a fluid of lower mobility displaces a fluid of higher mobility leading to interpenetration of two fluids at their interface in a porous medium or Hele-Shaw cell, generally in a form resembling fingers. When the less mobile (or more viscous) fluid displaces a more mobile (less viscous) fluid, the displacement is stable leading to a circular pattern between the two fluids in a Hele-Shaw cell. Persistence of interest in VF phenomena over the past three decades has often been justified because of its significance to secondary oil recovery wherein one is attempting to force petroleum out of one well by pumping a fluid down one or more nearby injection wells. Given the typically high viscosity of petroleum, this process generally results in fingering and a loss of sweeping or displacing efficiency (leading to a corresponding loss of product and money). However, VF is of broad significance since it can apply to any flows of two or more fluids in porous media such as hydraulic fracturing, pollution dispersal, polymer processing, mixing in combustion, magma flows, and flows in 
chromatography columns(Aldushin and Matkowsky 1998, Barati and Liang 2014, Berkowitz 2002, Perugini and Poli 2005, Shalliker et al. 2007). Viscous fingering is generally studied in Hele-Shaw cells, which are two flat plates, usually glass or Plexiglas, separated by a gap of less than a millimeter. Flows in Hele-Shaw cells are readily imaged. Furthermore, such flows can be modeled using Darcy's law for flow in porous media with the simple expedient of making the permeability proportional to the square of the gap width (Homsy 1987). Saffman and Taylor (Saffman and Taylor 1958) demonstrated using linear stability theory that when air is injected into a viscous fluid in a Hele-Shaw cell, the interface becomes unstable and results in a fingering pattern. The details of the instability depend on many factors such as miscibility or immiscibility (Homsy 1987), non-Newtonian properties of the fluids (Fontana et al. 2014), any anisotropy of the cell (Sarkar and Jasnow 1989), particle loading of a fluid (Xu et al. 2016), and the introduction of chemical reactions during the flow (Nagatsu et al. 2008).

VF is further divided into miscible and immiscible flows with quite different fundamental parameters. VF of immiscible flows depends on interfacial tension as expressed in the Capillary number. VF of miscible flows have historically been treated as experiencing no appreciable interfacial tension and have been characterized in terms of diffusion as expressed in the Péclet number, which is the ratio of convective to diffusive transport. (However, note that recent results have implicated an effective interfacial tension as active at the interface. (Beeson-Jones and Woods 2015, Borcia and Bestehorn 2009, Chen and Liu 2005, Chen et al. 2008, Hughes et al. 2012, Pramanik and Mishra 2014, Pramanik and Mishra 2015)) In both immiscible and miscible systems there are similar mechanisms present such as shielding and splitting of fingers which affect the way the pattern of the instability develops (Homsy 1987, Nagatsu et al. 2007). A gravity field is not necessary for VF to occur; however, three-dimensional effects arising from layered density differences in the gravity field have been shown to modulate the flow in some cases (Bunton et al. 2016, John et al. 2013, Oliveira and Meiburg 2011). Numerous computational and experimental investigations have demonstrated variations in viscous fingering if the two fluids involved can chemically react thereby changing the viscosity profile at the interface.

This paper focuses exclusively on a miscible, reactive system of one monomer displacing more viscous monomer with the possibility of a step-growth polymerization reaction where they meet or mix. The overarching goal is to test the prediction by Hejazi et al. that a non-monotonic viscosity profile at the interface of two fluids can stabilize VF with the range of viscosities over which stabilization can occur increasing with increasing Damköhler number, Da. Otherwise put, other things being equal, the likelihood of stabilization should increase with increasing Da. The Damköhler number, to be defined further below, is a dimensionless parameter that compares the rate of reaction to the rate of flow where "flow" generally refers to advection but may refer to diffusion and Taylor dispersion as well. Reactive VF 
characteristics in general also depend on whether the reaction results in a Newtonian or non-Newtonian fluid, especially for polymer reactions. As is demonstrated later, the system herein was designed and demonstrated to be Newtonian, which was essential for meaningful comparison to theory. By comparison some of the authors of the current work recently published a short study of reactive viscous fingering for the related system of a dithiol displacing a triacrylate fluid using the lower reactivity initiator, octylamine (Bunton et al. 2017). The presence of the triacrylate made cross-linking possible, which ultimately resulted in gelation. The systems did indeed appear more stable at intermediate levels of reaction rate. However, the flows were complicated -- perhaps even dominated -- by the presence of three-dimensional internal flows.

The goal of this study is to characterize if and when a non-monotonic viscosity profile produced by chemical reaction can stabilize an otherwise unstable flow interface in a Hele-Shaw cell as predicted by linear stability analysis of Hejazi. To accomplish this one needs a system with the following properties. (1) The displacing and displaced fluids in a Hele-Shaw cell should be unstable in the absence of reaction. (2) The reaction should be capable of increasing the viscosity of the reaction product fluid well above that of either reactant. (3) The rate of reaction should be both known and tunable. This means one can vary Da both by varying flow rate and reaction rate separately thus determining if any response is dependent primarily on the ratio and not some independent aspect of one or the other. (4) All fluids, and in particular the reaction product, should remain Newtonian throughout the flow. (5) Ideally, it should be possible to distinguish where and to what extent the reaction has occurred. The experiment described herein meets all of these requirements; although some to greater degree than others. The paper is therefore outlined as follows. First, we present a brief summary of prior work on chemical reactions and viscous fingering as well as approaches to stabilization of viscous fingering. Second, the model reactive fluid system is described in the context of the five requirements above. Third the experimental technique is summarized including reaction rates and imaging with an eye on imaging sensitivity to polymer conversion. Fourth, the choices of how to compute the Damköhler number are presented and justified. Fifth, the actual experimental results are presented and are interpreted in light of $\mathrm{Da}$, Péclet number, $\mathrm{Pe}$, and the linear stability analysis of Hejazi (Hejazi et al. 2010). Finally, conclusions are drawn and summarized.

\section{Background}

Chemical reactions have been shown experimentally and theoretically to impact viscous fingering. Nagatsu, et al. (Nagatsu, Hayashi, Ban, Kato and Tada 2008) showed how cross linking and concomitant gelation that occurred when a trivalent ion solution was injected into aqueous sodium polyacrylate resulted in a spiral pattern despite the experiment being performed in a radial geometry. Riolfo, et al. (Riolfo et al. 2012) demonstrated that reaction-driven viscous fingering developed 
when a more viscous solution displaced a less viscous one - a situation stable in the absence of reactions. Specifically, a polymer was used to displace less viscous water containing a $\mathrm{pH}$ changing reactant for a case where the polymer viscosity was $\mathrm{pH}$ dependent. They attributed the fingering to the buildup of a non-monotonic viscosity profile with patterns behind or ahead of the reaction zone depending on whether the product was more or less viscous than the reactant (Nagatsu, Matsuda, Kato and Tada 2007) also used dependence of polymer viscosity on $\mathrm{pH}$ to demonstrate changes in VF patterns caused by a chemical reaction where the reaction could either increase or decrease viscosity of the displaced fluid. The neutralization reaction was treated as instantaneous, implying a large Damköhler number in contrast to tuning the rate of reaction as proposed herein. Similar results were later obtained for the case where the viscosity change occurred in the displacing fluid (Nagatsu et al. 2010). Podgorski et al. have investigated fingering patterns between two reactive solutions initially of the same viscosity but forming a gel at their reactive interface (Podgorski et al. 2007). A variety of fingering instabilities was observed upon reaction between cetyltrimethylammonium bromide and salicylic acid forming wormlike micelles. (Note that the product gels were not Newtonian fluids in contrast to the system studied here.) Nagatsu and De Wit (Nagatsu and De Wit 2011) performed nonlinear numerical simulations of viscous fingering in the presence of infinitely fast chemical reactions (infinite Damköhler number). They characterized their system in terms of log mobility ratios of the reaction product to the displacing fluid and displaced fluid to displacing fluid for an $A+B \rightarrow C$ reaction. Differing viscosities could result in (1) a viscously unstable situation when the displacing fluid was less viscous than the displaced or (2) a hydrodynamically stable situation that could be destabilized by reaction. They numerically characterized six different possible viscosity profiles, four of which were non-monotonic and could lead to destabilization. Gerard and De Wit modeled the triggering of a $\mathrm{VF}$ instability by an $A+B \rightarrow C$ reaction in a two-dimensional porous medium as dependent on Damköhler number, contrast in viscosity between products and reactant, initial concentrations, and diffusion coefficients (Gérard and De Wit 2009). In particular they looked at the case where both initial fluids had the same viscosity, but the viscosity of the reaction product was greater. They confirmed the experimental results of Podgorski et al. (Podgorski, Sostarecz, Zorman and Belmonte 2007) that the VF pattern is different depending on which fluid is injected, despite the initial viscosities being the same, due to the different diffusion coefficients of the reactants. Of central importance herein, Hejazi et al. (Hejazi, Trevelyan, Azaiez and De Wit 2010) performed a linear stability analysis of $V F$ in the presence of an $A+B \rightarrow C$ reaction and classified possible scenarios dependent upon how $A, B$, and $C$ affect the viscosity and in particular whether a non-monotonic viscosity profile resulted. Their results and their relationship to this study are presented in more detail later herein. Other work has also indicated the importance of the mixing zone profiles to miscible, viscous flows. In a clever experiment wherein fingering was induced by a sudden increase in flow velocity in a packed column, Loggia et al. showed that the destabilization of the front due to 
mobility gradient decreased as the width of the gradient zone increased (Loggia et al. 1999). All of their initial gradients appear to be monotonic. Manickam and Homsy (Manickam and Homsy 1993) also studied non-monotonic viscosity profiles in viscous fingering using linear stability theory. They showed that a non-monotonic step profile could stabilize an otherwise unstable flow. However, their parametric study further showed that diffusion over long time eventually de-stabilized all such flows. Manickam and Homsy (Manickam and Homsy 1994) further obtained the interesting result that a non-monotonic viscosity profile could lead to "reverse fingering" where the displaced fluid fingered backwards into the displacing fluid. Clearly the mixing zone is of primary importance to miscible viscous fingering. From the reverse standpoint, viscous fingering affects mixing and can even be used intentionally when mixing is desired. Jha, Cueto-Felgueroso, and Juanes (Jha et al. 2011) modeled mixing by viscous fingering of miscible fluids of differing viscosity. They showed that such fingering led to the two competing effects of increased mixing from disorder induced in the velocity field and channeling of the low viscosity fluid resulting in it bypassing large portions of the higher-viscosity fluid. These authors later showed that mixing could be further increased and channeling decreased by alternating injection and viscous fingering (Jha et al. 2013).

Control of VF has often been a goal of investigation. Li et al. (Li et al. 2009) have numerically and experimentally demonstrated control of viscous fingering patterns in a Hele-Shaw cell by controlling the fluid injection rate. Dias et al. (Dias et al. 2010) theoretically predicted suppression of VF during piecewise-constant injection rate. Al-Housseiny et al. also showed that modifying flow geometry could control the systems. This was demonstrated by a stable flat interface of a typically unstable fluid flow in a converging Hele-Shaw cell (below a critical capillary number above which the flow transitioned back into unstable territory) (Al-Housseiny et al. 2012). Lastly, Riolfo et al. demonstrated using both experimental and theoretical studies that modifying the viscosity of the solutions could influence the onset and patterns of viscous fingering (Riolfo, Nagatsu, Iwata, Maes, Trevelyan and De Wit 2012). Numerous studies have also been done on the effects of chemical reactions on flows in vertical cells in the gravity field; however, these fall outside the scope of this research.

In this paper we investigate the effect of varying reaction rate and flow rate on VF of a polymer system as characterized by the Damköhler number. This research specifically focuses on control of di-functional monomer-monomer systems by varying initiator concentration and injection rate of a less viscous monomer displacing a more viscous monomer. Monomers in miscible solutions are brought into contact in a horizontal Hele-Shaw cell wherein step-growth polymerization occurs at the interface between the two fluids resulting in the production of a highly viscous fluid.

\section{Model System}


A dithiol monomer containing an initiator displaced a diacrylate monomer in a horizontal Hele-Shaw cell. Since only the displacing fluid contained initiator, the reaction only occurred when the two fluids met or mixed. Due to the difunctional nature of the two monomers, linear step growth polymerization occurred at the interface of the two fluids, where the polymer chain grew from either end by the addition of a monomer. For the system reported herein, the result was a Newtonian fluid of linear polymer with viscosity considerably higher than either monomer. Step-growth polymerization is a reaction in which difunctional or multifunctional monomers react to form first dimers, then trimers, longer oligomers and eventually long chain polymers (Odian 2004). If the functionality of at least one of the reactants is greater than two, a crosslinked product can be obtained. It was critical to use two difunctional monomers since monofunctional monomers merely lead to dimer formation with little change in viscosity, while reaction of a difunctional or higher monomer with a trifunctional or higher functionality monomer would result in crosslinking and likely non-Newtonian behavior. Significantly, the rate of this reaction can be tuned by varying the concentration and choice of the initiator. In all cases discussed herein the displacing fluid was 3,6-dioxa-1,8-octanedithiol (DODT) $>95 \%$ purchased from TCl America. The density of the dithiol was $1.12 \mathrm{~g} / \mathrm{cm}^{3}$ and its viscosity was measured to be 5.17 $\mathrm{mPa} s$ at $20^{\circ} \mathrm{C}$. The initiator was 1,8-diazabicyclo[5.4.0] undec-7-ene (DBU) purchased from Aldrich who report its density as $1.018 \mathrm{~g} / \mathrm{cm}^{3}$. The displaced diacrylate monomer was poly (ethylene glycol) diacrylate (PEGDA 575) also obtained from Aldrich where the 575 is the molecular weight in grams/mole. The density of PEGDA 575 was $1.12 \mathrm{~g} / \mathrm{cm}^{3}$ at $25^{\circ} \mathrm{C}$, and its viscosity was $78 \mathrm{mPa}$ s at $20^{\circ} \mathrm{C}$. Viscosities were measured using a Brookfield viscometer with small sample adapter. The two monomers had nearly identical densities while the displaced fluid was significantly more viscous than the displacing resulting in VF in the absence of a reaction. Concentration of initiator was measured in parts per hundred resin or phr; for example $1 \mathrm{phr}$ corresponds to adding $1 \mathrm{~g}$ initiator to $100 \mathrm{~g}$ dithiol. This reaction yields a highly viscous fluid that demonstrates predominantly Newtonian behavior and is not a gel as would have potentially been the case for higher functionalities of monomers. Rheology for varying initiator concentrations was performed at Tokyo Institute of Agriculture and Technology. Measurements of shear stress versus shear rate were consistent with the product being a Newtonian fluid for all but the highest concentrations of initiator, and even then the difference was small and only at high shear rates. In particular when the shear rate is smaller than $1400 \mathrm{~s}^{-1}$, normal stress is smaller than shear stress, and therefore the elastic property can be considered negligible. This is true for the systems utilized in this paper, verifying that the products of the chemical reactions are indeed Newtonian fluids. This is of critical importance since the computations to which we compare our results assumed Newtonian fluids and may well not apply to non-Newtonian systems.

\section{Experimental Technique}




\subsection{Flow and imaging}

Imaging was performed using a Schlieren imaging system consisting of a white light source, 15-cm diameter achromatic telescope objective lenses, a Hele-Shaw cell whose gap width could be varied, a 80-400-mm Nikkor f/4.5-5.6G lens on Nikon D810 camera with 36 megapixel sensor, and an adjustable iris at the Schlieren focal point. The system has been described in detail elsewhere (Bunton, Marin, Stewart, Meiburg and De Wit 2016). The top plate of the Hele-Shaw cell was held in place by placing masses on its edges. A syringe pump from syringepumps.com was used to inject the displacing fluid. A sample image is shown in figure 1 . Schlieren imaging is particularly appropriate for this study since it is sensitive to the polymerization reaction. In general, Schlieren imaging responds to gradients in index of refraction such as occur at the interface of two fluids of different densities. When the polymerization reaction occurs, there is a corresponding increase in refractive index resulting in a greater alteration in direction of the outgoing light, the end result being that region appears darker. Hence, a darker region in an image may either be because of an interface between displacing and displaced fluids or because of the polymerization reaction, or both. Usually it is not difficult to determine which cause (interface or polymer conversion) is the primary source of the darkening in the image by simple observation. Schlieren imaging is also a useful technique because no added dyes, color indicators, or molecular probes are required thus avoiding these potentially complicating factors. Almarcha et al. (Almarcha et al. 2010) demonstrated that color indicators can have a significant effect on flows in HeleShaw cells and should therefore be used cautiously as the results may not actually reflect the true nature of the flow.

\subsection{Reaction Rate Measurements}

Reaction rate measurements were necessary for calculating the Damköhler number. The displacing fluid DODT and the necessary amount of DBU initiator were added to a glass vial and mixed well. The DBU concentration was measured in parts per hundred resin (phr) relative to the mass of DODT. For example, a $1 \mathrm{phr}$ mixture of DBU in DODT would have $1 \mathrm{~g}$ of DBU for every $100 \mathrm{~g}$ of DODT. An equivalent mass of PEGDA 575 was added to this mixture, and the vial was shaken vigorously to ensure the formation of a homogeneous system. An aliquot was removed from the vial and placed in the liquid cell of a Bruker Tensor 27 FTIR equipped with a Pike Miracle single-bounce diamond attenuated total reflectance (ATR) cell. An FTIR spectrum was acquired every 10 seconds for twenty minutes. Data was acquired from $650-4000 \mathrm{~cm}^{-1}$ at a resolution of $4 \mathrm{~cm}^{-1}$ using 8 scans per spectrum. After acquisition, Bruker's OPUS software package was used to process the FTIR data. The spectra were smoothed using a 9-point smooth routine, and a baseline correction was performed using 10 iterations of the concave rubberband correction with 64 baseline points. The areas under the peaks of interest were determined using the built-in integration program. The peak bounds were determined visually 
and integration method B was used. The peak corresponding to the thiol groups was centered at $\sim 2560 \mathrm{~cm}^{-1}$. The acrylate groups were tracked using two separate peaks; one centered at $\sim 810 \mathrm{~cm}^{-1}$ and a doublet centered at $\sim 1630 \mathrm{~cm}^{-1}$ as seen in figure 2 . Using the peak area data, the conversion of the monomers over time was determined using the formula

$$
\text { Percentage Conversion }=\frac{M_{0}-M_{t}}{M_{0}} \times 100
$$

where $M_{0}$ is the initial monomer peak area and $M_{t}$ is the peak area at time $t$. The rate of reaction was calculated by finding the slope of the plot of conversion versus time. In each case, the time interval over which the rate was at its maximum was used. The reaction rate was determined using the signal from each FTIR peak, and these values were averaged. A minimum of three trials was conducted for each DBU concentration, the results were averaged; the standard deviation was reported in the form of error bars in figure 3.

At DBU concentrations above $0.01 \mathrm{phr}$, the polymerization proceeds too quickly to monitor via FTIR since during the time it takes to mix the components and place them onto the instrument ( $10-20$ seconds), the reaction is nearly complete. The concentrations used in the flow experiments were $0.1,0.25,0.50$, and $1.0 \mathrm{phr}$ for a $0.125 \mathrm{~mm}$ gap and $0.5,1.0,2.5$, and $5.0 \mathrm{phr}$ for the $0.35 \mathrm{~mm}$ and $0.65 \mathrm{~mm}$ gaps. In order to estimate the reaction rates for these DBU concentrations above $0.01 \mathrm{phr}$, data from several DBU concentrations at and below $0.01 \mathrm{phr}$ were used to construct an equation describing the increase in the average reaction rate with increasing DBU concentration by performing a linear fit on the plot of average rate versus DBU concentration. Using this fit equation, the approximate reaction rates at higher DBU concentrations were determined by extrapolation. (Previous work has shown that the reaction rate for the thiol-acrylate reaction is first order with respect to the initiator.(Chan et al. 2010)).

\section{Damköhler Number Calculation}

Flows were performed utilizing the same monomers but varying concentrations of the initiator DBU in parts per hundred resin (phr). Each flow was characterized by its Damköhler number, Da, which is the ratio of the hydrodynamic to chemical time scale (equivalently reaction rate to flow rate), that is

$$
D a=\frac{\tau_{\text {hyd }}}{\tau_{\text {chem }}} .
$$

There are multiple ways to calculate Da depending on the key variables in establishing the two timescales. Three approaches were tried, and the 
results of two are presented herein. First, following Hejazi (Hejazi, Trevelyan, Azaiez and De Wit 2010)one has

$$
D a=\frac{\tau_{\text {hyd }}}{\tau_{\text {chem }}}=\frac{D(2 \pi R b)^{2}}{Q^{2} \tau_{\text {chem }}}
$$

where $Q$ is the volume flow rate, $b$ is the gap width between the two plates in the Hele-Shaw cell (less than $1 \mathrm{~mm}$ ), $D$ is the diffusion coefficient, and $R$ is the radius of the fluid flow in the cell. This approach to determining the hydrodynamic timescale takes into account both advection and diffusion (but not Taylor dispersion, at least not directly). The necessity of including the diffusivity is discussed shortly. Experimentally, the Damköhler number was varied by altering the chemical time scale (e.g. concentration of the initiator) or the hydrodynamic time scale by varying the flow rate of the less viscous fluid being pumped into the cell. The values of the reaction time, $\tau_{c h e m}$, were taken as the inverse of the extrapolated reaction rates for the concentration of DBU in the experiment. Non-reactive systems (systems where no initiator was used) have $\mathrm{Da}=0$. Experiments were conducted at three gaps $0.125 \mathrm{~mm}, 0.35 \mathrm{~mm}$, and $0.65 \mathrm{~mm}$ to give a wider range of Da values as well to determine if the gap width had any independent effect on the fingering pattern of the flow. It was important to use a form of Da that accounted for diffusion as well as advection because the time for diffusion of half of the gap width was comparable to the time of the flow. In particular $b / 2=\sqrt{D \cdot t}$ yields a diffusion time of about $13 \mathrm{~s}$ for the $0.125 \mathrm{~mm}$ gap, $105 \mathrm{~s}$ for the $0.35 \mathrm{~mm}$ gap, and $364 \mathrm{~s}$ for the $0.65 \mathrm{~mm}$ gap. By way of comparison the longest flow times were $60 \mathrm{~s}$ for the $0.125 \mathrm{~mm}$ gap, $120 \mathrm{~s}$ for the $0.35 \mathrm{~mm}$ gap, and $240 \mathrm{~s}$ for the $0.65 \mathrm{~mm}$ gap. Hence, for many of the flows, there was ample time for diffusion across the gap. Keep in mind that the flows likely produce a Poiseuille profile across the gap; hence, diffusion can be occurring inward from top of the profile to bottom or bottom to top as indicated in figure 4. Of course as the reaction rate increases or as the reaction proceeds, the front profile likely becomes less parabolic, that is, a Poiseuille profile ceases to be a realistic model. Furthermore, it may be that the smallest gap of $0.125 \mathrm{~mm}$ leaves so little room between the Poiseuille profile and the plates that diffusion is of limited importance there. Alternatively, the distance over which diffusion has to occur to be significant is correspondingly smaller as well; hence, there may be competing issues at the smallest gap.

The second means of determining Da is from Nagatsu et al. (Nagatsu et al. 2009) and Fernandiz and Homsy (Fernandez and Homsy 2003) and is given by

$$
D a=\frac{\kappa b R_{0}^{2}}{2 q}
$$


where $\kappa$ is reaction rate, $b$ is gap width, $R_{0}$ is radius of flow, and $q$ is volume flow rate. Note that in the work by Nagatsu, et al. the reaction rate, $\kappa\left(\mathrm{s}^{-1}\right)$, was determined from viscosity measurements whereas herein it is determined from FTIR measurements. Nagatsu et al.'s approach is based on pure advection without accounting for diffusion. Da was calculated using both approaches as a means of potentially determining if diffusion had a significant role in the fingering. Note however that only Damköhler numbers calculated from eq. 3 can be numerically compared to the linear stability analysis of Hejazi, since that is the form used therein.

The third alternative to computing Da that seems appealing at face value is to use the rate of viscosity increase to determine a reaction rate. However, this is not viable as rapid reactions lead to lower final viscosities, not higher, in this context of linear step-growth polymerization. That is, faster reaction rate sactually leads to formation of a greater number of shorter polymer chains with a commensurate lower final viscosity than had they been longer chains formed more slowly. Nonetheless, for completeness, this third approach to calculating Da was tried with no meaningful correlation found.

A representative Da value was calculated using equation 3 for each of the flows in the figures 5, 6, and 7; that is, for the $0.125 \mathrm{~mm}, 0.35 \mathrm{~mm}$, and $0.65 \mathrm{~mm}$ gaps. Since a mutual diffusion coefficient was not known for our particular dithioldiacrylate system, we used the value of the mutual diffusion coefficient of 2chloroethylacrylate and 1,3-bis(3-methacryloxypropyl)-1,1,3,3-

tetramethyldisiloxane as determined by Leewis et al. (Leewis et al. 2004). The mutual diffusion coefficient of these (meth)acrylate monomers should be similar to that of our system and is reported as $(2.9+/-0.6) \times 10^{-10} \mathrm{~m}^{2} / \mathrm{s}$ at an equal concentration ratio. The Da value is termed "representative" since Da is expected to vary with the square of the radius of the flow. For a given gap, each image shown in a given figure corresponds to a fixed volume dispensed, that is, after 2.0 $\mathrm{mL}$ dispensed for the $0.65 \mathrm{~mm}$ gap, $1.0 \mathrm{~mL}$ for $0.35 \mathrm{~mm}$ gap, and $0.5 \mathrm{~mL}$ for the $0.125 \mathrm{~mm}$ gap. The radius used in computing Da was the radius that would correspond to these given volumes if the flow had been completely circular corresponding to complete stability. These radii are $31 \mathrm{~mm}$ for the $0.65 \mathrm{~mm}$ gap, $30 \mathrm{~mm}$ for the $0.35 \mathrm{~mm}$ gap, and $36 \mathrm{~mm}$ for the $0.125 \mathrm{~mm}$ gap. Reaction rates were determined as described above and the chemical time scale set as the reciprocal of the reaction rate. There is considerable uncertainty in the reaction rate because of the difficulty in FTIR measurements at high reaction rates discussed above and the corresponding necessity of extrapolation. Still, the predicted trends should be sufficiently accurate for meaningful conclusions. Damköhler values obtained varied from $3 \times 10^{-7}$ to $2 \times 10^{-1}$ spanning six orders of magnitude. Observe in figures 5-7 that a low injection rate results in a higher Da and in some cases a more stable flow. The stabilization of the flow definitely arises from the introduction 
of an initiator, and therefore the polymerization reaction, since flows of the same parameters and no initiator remained unstable, as one would expect.

\section{Experimental Results}

Results are shown in figures 5-7 and tables 1-3 for three gaps. Reaction rate increases going down a column and flow rate decreases across a row. Hence Da increases roughly diagonally from upper left-hand corner to lower right-hand corner. Da values are shown in the corresponding tables associated with each figure where each table entry corresponds to the same row and column of the flow in the figure. As noted above there is considerable uncertainty in the Da values because of extrapolation of the reaction rates, but the trends should still be reliable. When flows are compared, it is easy to observe the increase in stability as Da increases toward the lower right-hand corner (e.g. the last image on the bottom row of figures 5-7). This can be attributed to the fact that the injection rate becomes sufficiently low that the polymerization has time to occur at the interface between the fluids. The polymerization decreases the fingering instability of the fluids as discussed later and the rest of the flow presumably continues to occur behind the front. At the $1.0 \mathrm{~mL} / \mathrm{min}$ flow rate shown in the second to last column in each figure, the flows toward the bottom of the figure are relatively stable compared to the non-reactive case at the same injection rate. Once the flow rate increases even more (e.g. the third image from right of each row) the fingering begins to outrun the polymerization reaction which is why in the bottom images the darkness representing the high viscosity polymerization appears trailing behind tips of the fingers at least for the $0.35 \mathrm{~mm}$ and $0.65 \mathrm{~mm}$ gaps. This is evidence that the fluid is moving too quickly for the polymerization to keep up, resulting in polymerization behind the leading edge of the fingering. That is, the fingering interface outruns the polymerization front as Da decreases significantly. For these cases the outer boundary is largely the same as for $\mathrm{Da}=0$.

In tables 5-7 the Damköhler values in bold red font indicate cases that by eye correspond to flow stability or at least approximate stability. There is perhaps some agreement between the $0.35 \mathrm{~mm}$ gap values and the $0.65 \mathrm{~mm}$ gap values where increased stability seems to occur for $\mathrm{Da}$ of order $10^{-3}-10^{-2}$. For the $0.125 \mathrm{~mm}$ gap stability occurs at a Da of order $10^{-5}-10^{-4}$, i.e., one to two orders of magnitude lower. Apparently narrower gap favors stabilization for these reactive flows. The reason for this is not known. We remark that in classical viscous fingering experiments, the instability does not depend on the gap width in isolation, but on the Péclet number $\mathrm{Pe}=\mathrm{Q} /(2 \pi \mathrm{bD})$ where $\mathrm{Q}$ is the volume flow rate, $\mathrm{b}$ is the gap width, and $\mathrm{D}$ denotes the diffusivity. The trend of how the growth rate varies with $\mathrm{Pe}$ can be qualitatively different for large $\mathrm{Pe}$, where thin films of the resident fluid are left behind on the walls of the Hele-Shaw cell, and for small Pe, where no such films exist. In any event clearly Da alone cannot capture all of the information related to stabilization for narrow gaps. The above discussion focused on change in Da from 
changing flow rate. However, the discussion can equally well be cast in terms of increasing reaction rate by comparisons going down a column moving toward increasing stability, at least for the right-hand sides of the figures. Hence for a given gap size both flow rate and reaction rate must be taken into account, and these are captured by Da.

Péclet numbers were also calculated for each gap using the approach of Nagatsu et al. (Nagatsu, Matsuda, Kato and Tada 2007)

$$
P e=\frac{Q}{2 \pi b D}
$$

where $Q$ is the volume flow rate, $b$ is the gap width, and $D$ is the diffusivity. Pe varied from $7.0 \times 10^{4}$ to $1.1 \times 10^{7}$ and is therefore always large. This suggests that advection dominates over diffusion. However, this simple interpretation is complicated by the narrowness of the gaps, by the radial geometry of the displacement, and by the essential role of diffusion in initiating the chemical reaction. Since Taylor dispersion is more significant at high Péclet numbers (Petitjeans et al. 1999, Taylor 1953), the mixing that leads to the polymerization reaction is likely enhanced by Taylor dispersion. On the other hand, due to the radial nature of the flow, the effective frontal velocity decreases with time, which should reduce Taylor dispersion and enhance the stability of the front (Chui et al. 2015) for late times. In addition, this effect could provide the polymer chains with more time to increase their length to become longer during the later stages of the experiment.

The linear stability analysis of reactive flow in a Hele-Shaw cell by Hejazi et al. can be used to interpret these flow results. Their results indicate that at time zero, regions of stability or instability of the reactive flow depends on the log mobility or viscosity ratios of the fluids (Hejazi, Trevelyan, Azaiez and De Wit 2010). That is,

$$
R_{B}=\ln \left(\frac{\mu_{B}}{\mu_{A}}\right)
$$

$$
R_{C}=\ln \left(\frac{\mu_{C}}{\mu_{A}}\right)
$$

where $R_{B}$ is the log viscosity ratio of the displaced fluid to the displacing and $R_{C}$ is the log viscosity ratio of the reaction product fluid to the displacing fluid. They categorized their results according to whether the viscosity profile at the front was monotonic or non-monotonic and, if non-monotonic, whether the reaction increased the viscosity above that of the highest viscosity fluid or decreased it below that of the lowest viscosity fluid. They further characterized their results as to whether the non-monotonic portion of the profile was on the leading or trailing edge of the front. 
This resulted in six regions of behavior in a parameter plane of $R_{C}$ versus $R_{B}$. Our results correspond to the case where the unreactive flow is unstable and the reaction leads to an increase in viscosity at the leading edge of the front (region III in their figure 3 (Hejazi, Trevelyan, Azaiez and De Wit 2010)). Their results show that at time zero this viscosity profile stabilizes an otherwise unstable flow at least for infinite Da. However, their results also show that the long-time behavior of all categories of reactive flows are ultimately less stable in the presence of a chemical reaction that alters the viscosity with the exception of a flow that maintains a monotonically decreasing viscosity at the front. This result that was confirmed by nonlinear simulations for infinite Da (Nagatsu and De Wit 2011).

Hejazi et al. further calculated regions of stability and instability in the $R_{C} R_{B}$ plane for various $\mathrm{Da}$ values at time zero. The work herein specifically corresponds to the case where the viscosity of the reaction product is much greater than that of either the displacing or displaced fluid. That is, $\mu_{\mathrm{C}}>\mu_{\mathrm{A}}$ and $\mu_{\mathrm{C}}>\mu_{\mathrm{B}}$. Given these and the fact that viscosity-increasing polymerization occurs at or behind the front, and further given that fresh un-polymerized fluid is continually flowing from the injection point, it must be that a maximum in viscosity occurs somewhere at or behind the front thus implying a non-monotonic viscosity profile.

Rheometry measurements were used to further characterize the system. Figure 8 shows the viscosity as a function of shear rate. The product is clearly a Newtonian fluid except for some variation at the highest shear rates for the highest initiator concentration (and therefore highest reaction rate). Certainly, shear occurs when forcing fluids between the plates of a Hele-Shaw cell; however, except for very near the entrance port, the shear rate should be less than the $1000 \mathrm{l} / \mathrm{s}$. These final viscosities are also very large compared to the viscosities of the reactants (i.e., the displaced and displacing fluids). The dithiol had a viscosity of as $5 \mathrm{mPa}$. 5 and PEGDA (575) a viscosity of $78 \mathrm{mPa} \cdot \mathrm{s}$. Given sufficient time the final reaction product of dithiol-diacrylate linear polymer resulted in a viscosity between 1000 and 2000 $\mathrm{mPa} \cdot \mathrm{s}$. This may not be indicative of the viscosity at the interface between the displacing and displaced fluid but it is reasonable to expect a significantly nonmonotonic viscosity profile at the interface for sufficiently high reaction rate. Note the viscosity does NOT increase with increasing initiator concentration. This seemingly counter-intuitive result is easily explained. When the reaction rate is low, short polymer chains have time to grow into longer chains before the formation of many additional chains. When the reaction rate is high, a greater number of shorter chains are formed resulting in a lower viscosity than for low reaction rates. This behavior is well understood in the polymer community (Odian 2004).

If we assume a value for the viscosity of the reaction product between $1000 \mathrm{mPa} \cdot \mathrm{s}$ and $10,000 \mathrm{mPa} \cdot \mathrm{s}$, and given the viscosity of the dithiol as $5 \mathrm{mPa} \cdot \mathrm{s}$, this gives logarithmic viscosity ratios of between 5 and 7.6 for the reaction product to the displacing fluid. Given a viscosity of $78 \mathrm{mPa} \cdot \mathrm{s}$ for the displaced fluid (PEGDA), one 
arrives at a log viscosity ratio of 2.7 for displaced to displacing fluid. Taking 1000 $\mathrm{mPa} s$ as a potentially low representative value of the viscosity of the reaction product yields $R_{c} \sim 5.3$ and taking $10000 \mathrm{mPa}$ s as representative yields $R_{c} \sim 7.6$. Keep in mind there may be significantly higher viscosity at the local flow interface than for the uniformly mixed solutions used for the viscosity measurements. Using the graph of Da dependence at time zero from Hejazi et al., figure 5, we can estimate the $D a$ value that should stabilize a flow with these log mobility ratios. For $R_{B} \sim 2.7$ and $R_{C} \sim 7$, stabilization would be expected around $\mathrm{Da}>0.5$. This is larger than the tabulated values herein, but given the uncertainties in reaction rates and in the viscosity of the reaction product, it is not unreasonable.

From the experimental data taken of chemically reactive fluid systems at various gaps, it has been observed that the resulting viscous fingering depends on the injection rate of the less viscous fluid, the reaction rate of the two chemicals, and appropriate viscosity ratios. The first two parameters upon which the fingering depends are components of the Damköhler number, which was determined for each flow in order to understand the correlation between the reactivity and injection rate to the resultant fingering pattern. The data show, loosely speaking, that if the flow rate is greater than the reaction rate, traditional viscous fingering will occur, as the fingers will outrun the polymerization reaction. This was observed in several of the high flow rate experiments. Again loosely speaking, if reaction rate is greater than flow rate, then the resulting system may be stable because of polymerization occurring at the interface between the two fluids and the resulting high viscosity product leading to a non-monotonic viscosity profile. The observed correlation between $\mathrm{Da}$, viscosity ratio, and transition between stability is in agreement with the trends in the time equal zero results of Hejazi et al (Hejazi, Trevelyan, Azaiez and De Wit 2010). At longer times the flow should be unstable based on their results. Given their non-dimensional time definition of $t=D / U^{2}$ where $D$ is the diffusivity and $U$ is the front velocity, an estimate of the dimensional time step is of order a few milliseconds. So even for the shortest flows, one would expect longtime behavior. Yet, the time zero stabilization does seem to occur. Worth noting is that their calculation is two-dimensional and does not capture the three-dimensional nature of the front profile. Furthermore, for the radial flow of the experiments herein, Da would be a function of time whereas we have computed representative values.

\section{Conclusion}

We demonstrated stabilization of viscous fingering by a polymerization reaction that produced a highly viscous reaction product at or behind the front during viscous fingering. The rate of reaction was tunable via concentration of initiator. This combined with varying the flow rate of the displacing fluid via a syringe pump allowed for an investigation of stabilization as a function of Damköhler number. Stabilization was observed for sufficiently high Da for three different Hele-Shaw cell 
gaps. Da values ranged over six orders of magnitude. Results were compared to predictions of the linear stability analysis of Hejazi et al (Hejazi, Trevelyan, Azaiez and De Wit 2010), which predicted stabilization above a set of Da values dependent upon the log viscosity ratios of the reaction product to the displacing fluid and the displaced fluid to the displacing fluid. While results were not in numerical agreement with linear stability analysis, given the uncertainties in viscosity of the reaction product as well as the reaction rate, they are at least in the right regime of log viscosity ratios and $\mathrm{Da}$ values and more importantly follow the same trends. Our data showed that at sufficiently high Da values, the VF flows could be stabilized. We further observed that stabilization occurs at lower Da for narrower gaps; that is, narrow gaps favor stabilization for these reactive flows. Hence Da alone cannot capture all of the relevant dynamics. Péclet numbers were computed and determined to be large suggesting that advection dominates over diffusion.

\section{Acknowledgements}

We thank William Jewell College students Macy Tush, Charles Bradfield, and Erika Storvick for their contributions to data acquisition. Thanks to Samuel Bynum of Louisiana State University for assistance with FTIR data collection. Thanks to Professor Yuichiro Nagatsu of the Tokyo University of Agriculture and Technology for viscosity measurements and fruitful discussions. We thank Professor A. De Wit of Nonlinear Physical Chemistry Unit, Service de Chimie Physique et Biologie Théorique, Université libre de Bruxelles for numerous discussions of these issues. This work was supported by the National Science Foundation Grants CBET-1335739 and CBET- 1438052. 


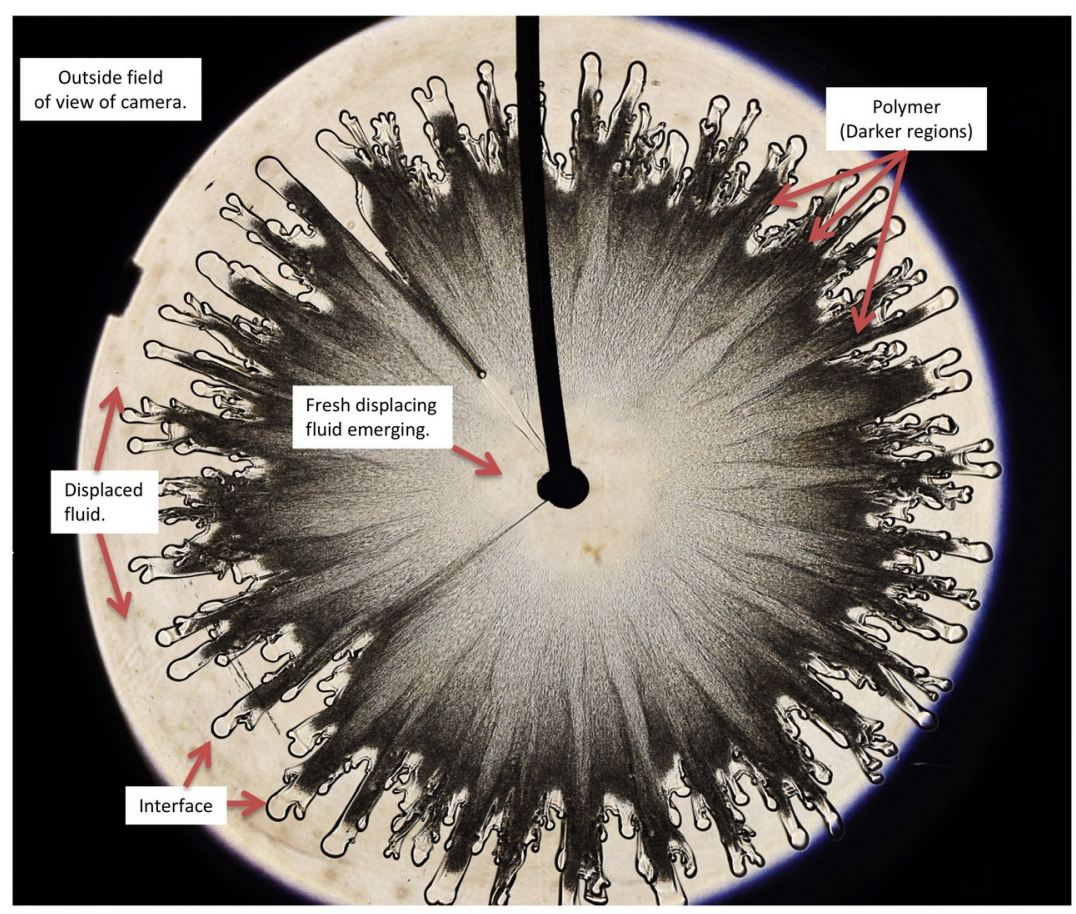

Fig. 1 Schlieren image of dithiol (DODT containing initiator DBU) displacing dicrylate (PEGDA) in a Hele-Shaw cell. The regions of greater polymer conversion from reaction are darker. In this example the reaction is seen to trail behind the front. Parameters: $0.5 \mathrm{phr}$ DBU in DODT displacing PEGDA 575, $0.35 \mathrm{~mm}$ gap, 10.0 $\mathrm{mL} / \mathrm{min}$. Field of view is $\sim 12 \mathrm{~cm}$ 
Fig. 2 Example FTIR spectral regions for a) the acrylate peak centered at $\sim 810 \mathrm{~cm}^{-1}$ and b) the acrylate doublet centered at $\sim 1630 \mathrm{~cm}^{-1}$ during the first 6 minutes of a polymerization reaction. 


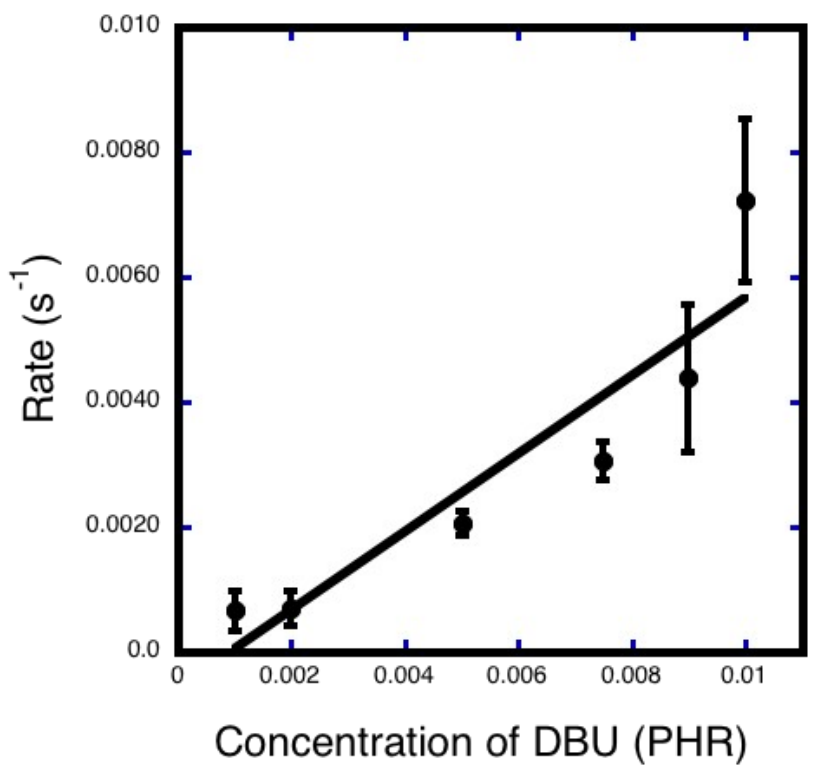

Fig. 3 Reaction rates of step-growth polymerization of DT and PEGDA initiated by DBU as measured by FTIR 


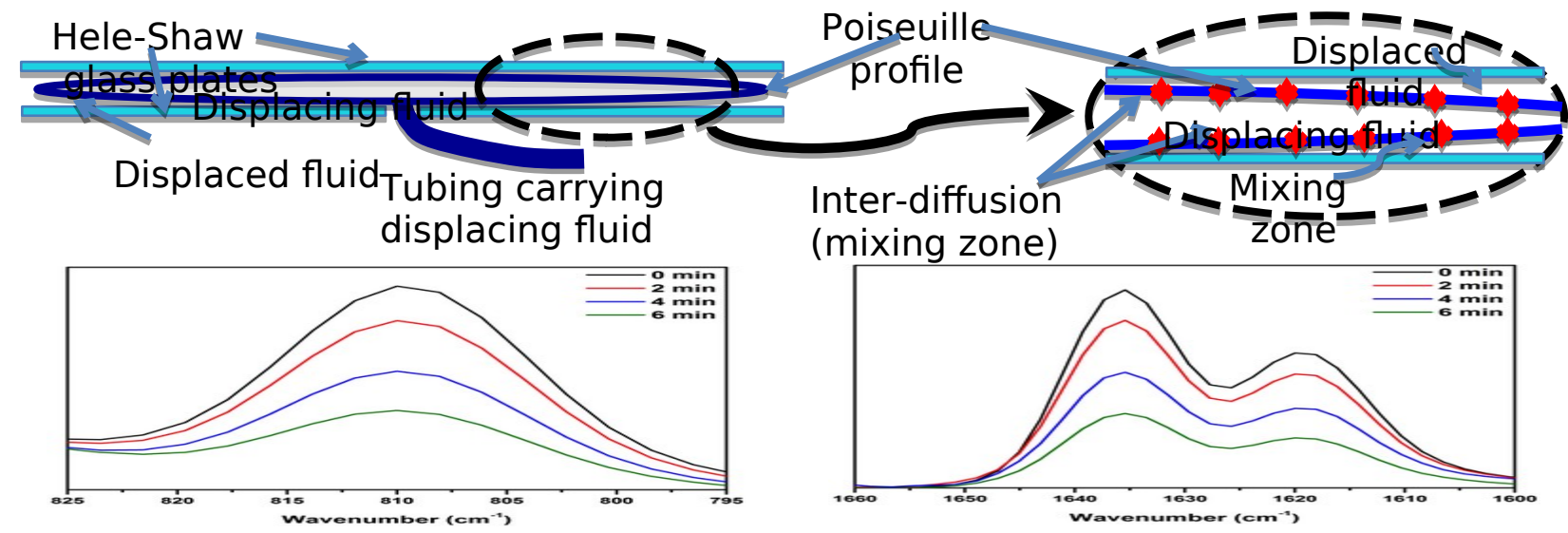

Fig. 4 Schematic of flow profile between the plates of the Hele-Shaw cell highlighting reaction region. The double-ended arrows in the highlighted zone are intended to represent the mixing at the front because of diffusion and Taylor dispersion 


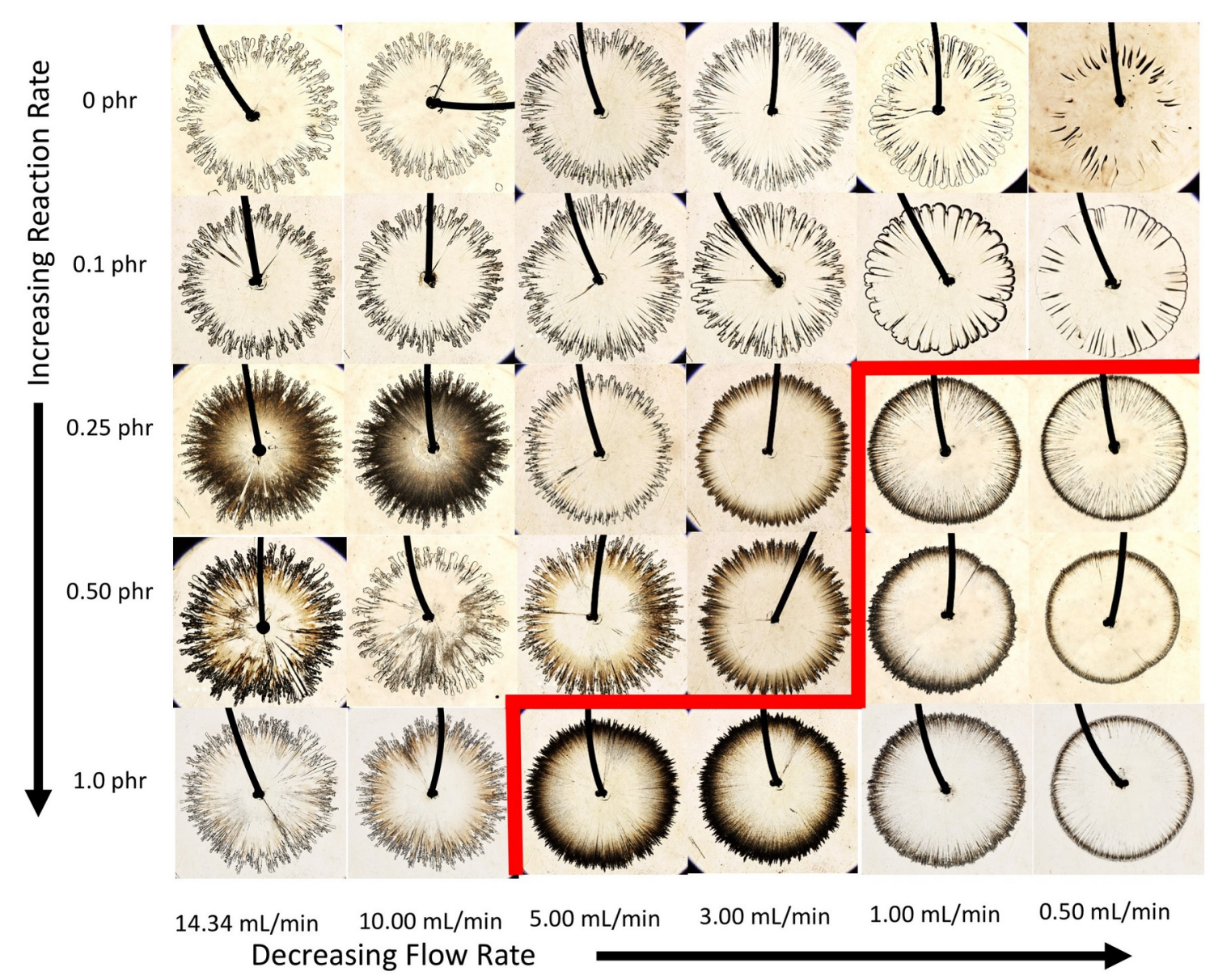

Fig. 5 VF of DT displacing PEGDA 575 as a function of initiator concentration and flow rates for a $0.125 \mathrm{~mm}$ gap. Table 1 shows corresponding DBU initiator concentrations, flow rates, and Damköhler numbers. Flows to right of and below red line are deemed to be stable or at least near stability. Shaded areas of table are deemed to represent stable flow or at least close to stability. Times listed for each column correspond to when $0.5 \mathrm{~mL}$ of displacing fluid has been dispensed.

Brightness and contrast of individual images were increased by up to $40 \%$ to bring the intensities into closer agreement. Most images in this figure were sharpened some as well. 
Table 1a Damköhler numbers calculated using equation 3 for DBU initiator concentrations and flow rates corresponding to VF of DT displacing PEGDA 575 of figure 5. Entries in bold red type are deemed to represent flow close to stability.

\begin{tabular}{|c|c|c|c|c|c|c|c|}
\hline \multicolumn{8}{|c|}{$0.125 \mathrm{~mm}$ gap - Da Approach 1} \\
\hline \multirow{2}{*}{$\begin{array}{c}\text { DBU } \\
\text { Conce } \\
\text { ntratio } \\
n \\
\text { (phr) }\end{array}$} & \multirow{2}{*}{$\begin{array}{l}\text { Tau } \\
\text { Chemic } \\
\text { al (s) }\end{array}$} & \multicolumn{6}{|c|}{ Damköhler Number, Da } \\
\hline & & $\begin{array}{c}14.34 \\
(\mathrm{~mL} / \mathrm{min})\end{array}$ & $\begin{array}{c}10.00 \\
(\mathrm{~mL} / \mathrm{min})\end{array}$ & $\begin{array}{c}5.00 \\
(\mathrm{~mL} / \mathrm{min})\end{array}$ & $\begin{array}{c}3.00 \\
(\mathrm{~mL} / \mathrm{min})\end{array}$ & $\begin{array}{c}1.00 \\
(\mathrm{~mL} / \mathrm{min})\end{array}$ & $\begin{array}{c}0.50 \\
(\mathrm{~mL} / \mathrm{min})\end{array}$ \\
\hline 0 & $\infty$ & 0 & 0 & 0 & 0 & 0 & 0 \\
\hline 0.10 & 16 & $2.6 \times 10^{-}$ & $5.3 \times 10^{-7}$ & $2.1 \times 10^{-6}$ & $5.8 \times 10^{-6}$ & $5.3 \times 10^{-5}$ & $2.1 \times 10^{-4}$ \\
\hline 0.25 & 6.4 & $6.4 \times 10^{-}$ & $1.3 \times 10^{-6}$ & $5.2 \times 10^{-6}$ & $1.5 \times 10^{-5}$ & $1.3 \times 10^{-4}$ & $5.2 \times 10^{-4}$ \\
\hline 0.50 & 3.2 & ${ }_{6}^{1.3 \times 10^{-}}$ & $2.6 \times 10^{-6}$ & $1.0 \times 10^{-6}$ & $2.9 \times 10^{-5}$ & $2.6 \times 10^{-4}$ & $1.0 \times 10^{-3}$ \\
\hline 1.00 & 1.6 & ${ }_{6}^{2.5 \times 10^{-}}$ & $5.2 \times 10^{-6}$ & $2.1 \times 10^{-5}$ & $5.8 \times 10^{-5}$ & $5.2 \times 10^{-4}$ & $2.1 \times 10^{-3}$ \\
\hline
\end{tabular}

Table 1b Damköhler numbers calculated using equation 4 for DBU initiator concentrations and flow rates corresponding to VF of DT displacing PEGDA 575 of figure 5. Entries in bold red type are deemed to represent flow close to stability.

\begin{tabular}{|c|c|c|c|c|c|c|c|}
\hline \multicolumn{8}{|c|}{$0.125 \mathrm{~mm}$ gap - Da Approach 2} \\
\hline \multirow{2}{*}{$\begin{array}{c}\text { DBU } \\
\text { Conce } \\
\text { ntratio } \\
n \\
\text { (phr) }\end{array}$} & \multirow{2}{*}{$\begin{array}{l}\text { Tau } \\
\text { Chemic } \\
\text { al (s) }\end{array}$} & \multicolumn{6}{|c|}{ Damköhler Number, Da } \\
\hline & & $\begin{array}{c}14.34 \\
(\mathrm{~mL} / \mathrm{min})\end{array}$ & $\begin{array}{c}10.00 \\
(\mathrm{~mL} / \mathrm{min})\end{array}$ & $\begin{array}{c}5.00 \\
(\mathrm{~mL} / \mathrm{min})\end{array}$ & $\begin{array}{c}3.00 \\
(\mathrm{~mL} / \mathrm{min})\end{array}$ & $\begin{array}{c}1.00 \\
(\mathrm{~mL} / \mathrm{min})\end{array}$ & $\begin{array}{c}0.50 \\
(\mathrm{~mL} / \mathrm{min})\end{array}$ \\
\hline 0 & $\infty$ & 0 & 0 & 0 & 0 & 0 & 0 \\
\hline 0.10 & 16 & 0.02 & 0.03 & 0.06 & 0.10 & 0.31 & 0.61 \\
\hline 0.25 & 6.4 & 0.05 & 0.08 & 0.15 & 0.25 & 0.76 & 1.53 \\
\hline 0.50 & 3.2 & 0.11 & 0.15 & 0.30 & 0.51 & 1.52 & 3.04 \\
\hline 1.00 & 1.6 & 0.21 & 0.30 & 0.61 & 1.01 & 3.04 & 6.08 \\
\hline
\end{tabular}




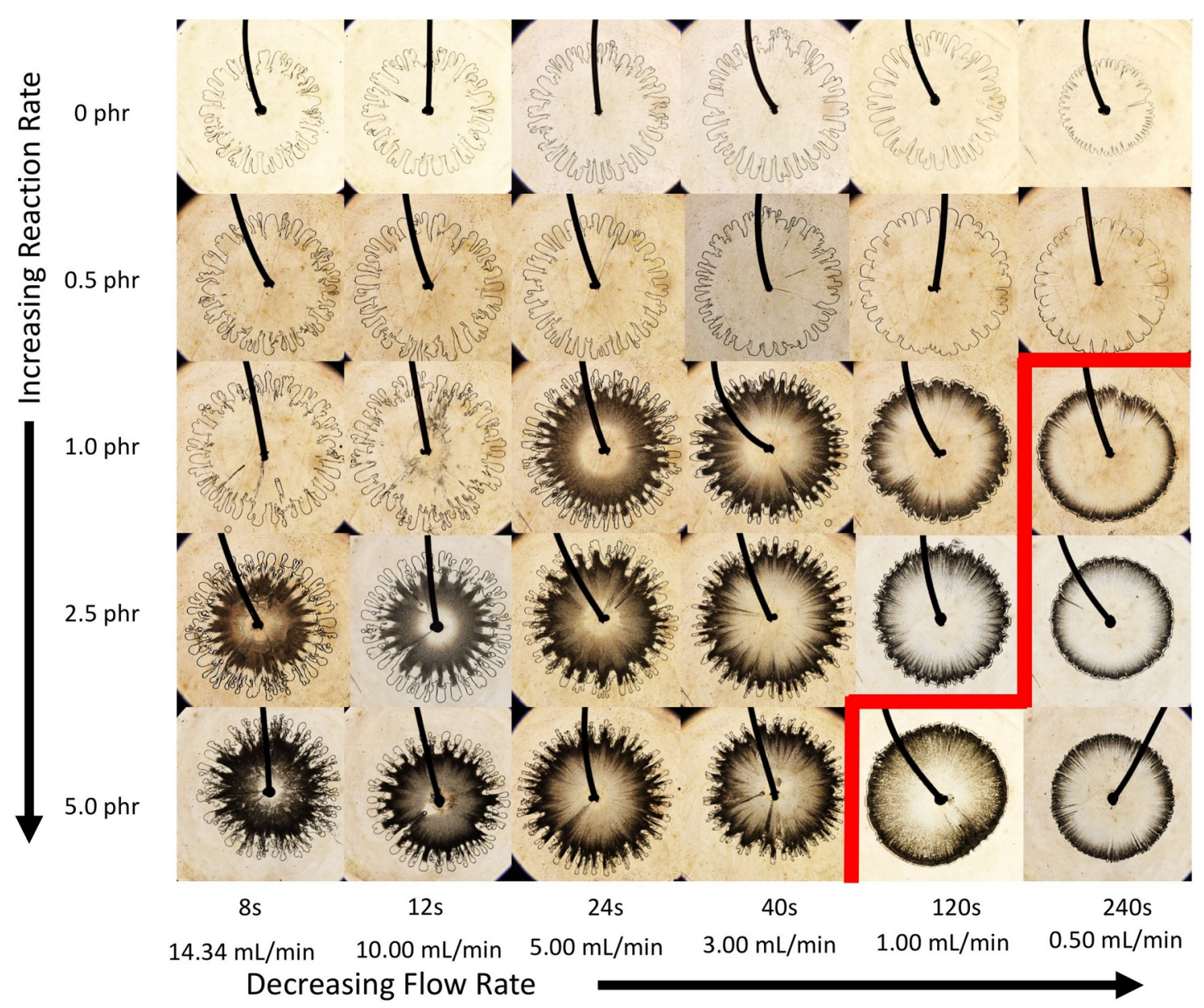

Fig. 6 VF of DT displacing PEGDA 575 as a function of initiator concentration and flow rates for a $0.35 \mathrm{~mm}$ gap. Table shows corresponding DBU initiator concentrations, flow rates, and Damköhler numbers. Times listed for each column correspond to when $1.0 \mathrm{~mL}$ of displacing fluid has been dispensed. Flows to right of and below red line are deemed to be stable or at least near stability. Shaded areas of table are deemed to represent stable flow or at least close to stability. Brightness and contrast of individual images were increased by up to $40 \%$ to bring the intensities into closer agreement. 
Table 2a Damköhler numbers calculated using equation 3 for DBU initiator concentrations and flow rates corresponding to VF of DT displacing PEGDA 575 of figure 6 . Entries in bold red type are deemed to represent flow close to stability.

\begin{tabular}{|c|c|c|c|c|c|c|c|}
\hline \multicolumn{7}{|c|}{$0.35 \mathrm{~mm}$ gap - Da Approach 1 } \\
\hline $\begin{array}{c}\text { DBU } \\
\text { Conce } \\
\text { ntratio } \\
\mathrm{n}\end{array}$ & $\begin{array}{c}\text { Tau } \\
\text { Chemic } \\
\text { al (s) }\end{array}$ & $\begin{array}{c}14.34 \\
(\mathrm{~mL})\end{array}$ & $\begin{array}{c}10.00 \\
(\mathrm{~mL} / \mathrm{min})\end{array}$ & $\begin{array}{c}5.00 \\
(\mathrm{~mL} / \mathrm{min})\end{array}$ & $\begin{array}{c}3.00 \\
(\mathrm{~mL} / \mathrm{min})\end{array}$ & $\begin{array}{c}1.00 \\
(\mathrm{~mL} / \mathrm{min})\end{array}$ & $\begin{array}{c}0.50 \\
(\mathrm{~mL} / \mathrm{min})\end{array}$ \\
\hline 0 & $\infty$ & 0 & 0 & 0 & 0 & 0 & 0 \\
\hline 0.5 & 3.19 & $\begin{array}{l}6.9 \times 10^{-} \\
6\end{array}$ & $1.4 \times 10^{-5}$ & $5.7 \times 10^{-5}$ & $1.6 \times 10^{-4}$ & $1.4 \times 10^{-3}$ & $5.7 \times 10^{-3}$ \\
\hline 1.0 & 1.60 & $\begin{array}{l}1.4 \times 10^{-} \\
5\end{array}$ & $2.8 \times 10^{-5}$ & $1.1 \times 10^{-4}$ & $3.2 \times 10^{-4}$ & $\mathbf{2 . 8 \times 1 0 ^ { - 3 }}$ & $\mathbf{1 . 1 \times 1 0 ^ { - 2 }}$ \\
\hline 2.5 & 0.64 & $\begin{array}{l}3.5 \times 10^{-} \\
5\end{array}$ & $7.1 \times 10^{-5}$ & $2.8 \times 10^{-4}$ & $7.9 \times 10^{-4}$ & $\mathbf{7 . 1 \times 1 0 ^ { - 3 }}$ & $\mathbf{2 . 8 \times 1 0 ^ { - 2 }}$ \\
\hline 5.0 & 0.32 & $\begin{array}{c}6.9 \times 10^{-} \\
5\end{array}$ & $1.4 \times 10^{-4}$ & $\mathbf{5 . 7 \times 1 0 ^ { - 4 }}$ & $\mathbf{1 . 6 \times 1 0 ^ { - 3 }}$ & $\mathbf{1 . 4 \times 1 0 ^ { - 2 }}$ & $\mathbf{5 . 7 \times 1 0 ^ { - 2 }}$ \\
\hline
\end{tabular}

Table 2b Damköhler numbers calculated using equation 4 for DBU initiator concentrations and flow rates corresponding to VF of DT displacing PEGDA 575 of figure 6 . Entries in bold red type are deemed to represent flow close to stability.

\begin{tabular}{|c|c|c|c|c|c|c|c|}
\hline \multicolumn{8}{|c|}{$0.35 \mathrm{~mm}$ gap - Da Approach 2} \\
\hline \multirow{2}{*}{$\begin{array}{c}\text { DBU } \\
\text { Conce } \\
\text { ntratio } \\
n \\
\text { (phr) } \\
\end{array}$} & \multirow{2}{*}{$\begin{array}{c}\text { Tau } \\
\text { Chemic } \\
\text { al (s) }\end{array}$} & \multicolumn{6}{|c|}{ Damköhler Number, Da } \\
\hline & & $\begin{array}{c}14.34 \\
(\mathrm{~mL} / \mathrm{min})\end{array}$ & $\begin{array}{c}10.00 \\
(\mathrm{~mL} / \mathrm{min})\end{array}$ & $\begin{array}{c}5.00 \\
(\mathrm{~mL} / \mathrm{min})\end{array}$ & $\begin{array}{c}3.00 \\
(\mathrm{~mL} / \mathrm{min})\end{array}$ & $\begin{array}{c}1.00 \\
(\mathrm{~mL} / \mathrm{min})\end{array}$ & $\begin{array}{c}0.50 \\
(\mathrm{~mL} / \mathrm{min})\end{array}$ \\
\hline 0 & $\infty$ & 0 & 0 & 0 & 0 & 0 & 0 \\
\hline 0.5 & 3.19 & 0.2 & 0.3 & 0.6 & 1.0 & 4.0 & 5.9 \\
\hline 1.0 & 1.60 & 0.4 & 0.6 & 1.2 & 2.0 & 5.9 & 11.8 \\
\hline 2.5 & 0.64 & 1.0 & 1.5 & 3.0 & 4.9 & 14.8 & 29.6 \\
\hline 5.0 & 0.32 & 2.1 & 3.0 & 5.9 & 9.9 & 29.6 & 59.1 \\
\hline
\end{tabular}




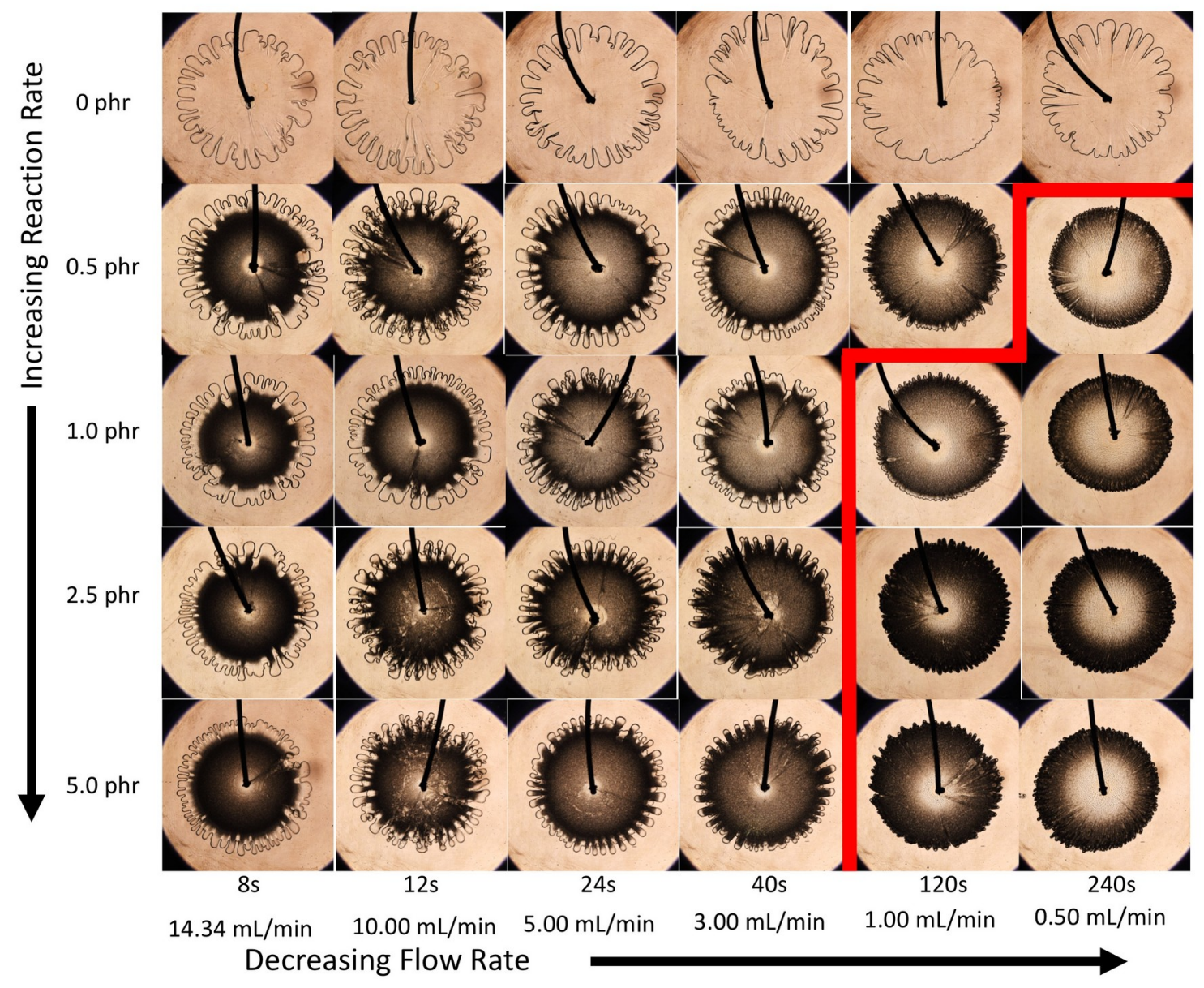

Fig. 7 VF of DT displacing PEGDA 575 as a function of initiator concentration and flow rates for a $0.65 \mathrm{~mm}$ gap. Table shows corresponding DBU initiator concentrations, flow rates, and Damköhler numbers. Flows to right of and below red line are deemed to be stable or at least near stability. Times listed for each column correspond to when $2.0 \mathrm{~mL}$ of displacing fluid has been dispensed. Shaded areas of table are deemed to represent stable flow or at least close to stability. Image brightness increased by $40 \%$ and contrast increased by $20 \%$. 
Table 3a Damköhler numbers calculated using equation 3 for DBU initiator concentrations and flow rates corresponding to VF of DT displacing PEGDA 575 of figure 7. Entries in bold red type are deemed to represent flow close to stability.

\begin{tabular}{|c|c|c|c|c|c|c|c|}
\hline \multicolumn{7}{|c|}{$0.65 \mathrm{~mm}$ gap - Da Approach 1 } \\
\hline $\begin{array}{c}\text { DBU } \\
\text { Conce } \\
\text { ntratio } \\
\mathrm{n} \\
(\mathrm{phr})\end{array}$ & $\begin{array}{c}\text { Tau } \\
\text { Chemic } \\
\text { al }(\mathrm{s})\end{array}$ & $\begin{array}{c}14.34 \\
(\mathrm{~mL} / \mathrm{min})\end{array}$ & $\begin{array}{c}10.00 \\
(\mathrm{~mL} / \mathrm{min})\end{array}$ & $\begin{array}{c}5.00 \\
(\mathrm{~mL} / \mathrm{min})\end{array}$ & $\begin{array}{c}3.00 \\
(\mathrm{~mL} / \mathrm{min})\end{array}$ & $\begin{array}{c}1.00 \\
(\mathrm{~mL} / \mathrm{min})\end{array}$ & $\begin{array}{c}0.50 \\
(\mathrm{~mL} / \mathrm{min})\end{array}$ \\
\hline 0 & $\infty$ & 0 & 0 & 0 & 0 & 0 & 0 \\
\hline 0.5 & 3.19 & $\begin{array}{l}2.5 \times 10^{-} \\
5\end{array}$ & $5.2 \times 10^{-5}$ & $2.1 \times 10^{-4}$ & $5.8 \times 10^{-4}$ & $5.2 \times 10^{-3}$ & $2.1 \times 10^{-2}$ \\
\hline 1.0 & 1.60 & $\begin{array}{l}5.1 \times 10^{-} \\
5\end{array}$ & $1.0 \times 10^{-4}$ & $4.2 \times 10^{-4}$ & $1.2 \times 10^{-3}$ & $\mathbf{1 . 0 \times 1 0 ^ { - 2 }}$ & $\mathbf{4 . 2 \times 1 0 ^ { - 2 }}$ \\
\hline 2.5 & 0.64 & $\begin{array}{l}1.3 \times 10^{-} \\
4\end{array}$ & $2.6 \times 10^{-4}$ & $1.0 \times 10^{-3}$ & $2.9 \times 10^{-3}$ & $\mathbf{2 . 6 \times 1 0 ^ { - 2 }}$ & $\mathbf{1 . 0 \times 1 0 ^ { - 1 }}$ \\
\hline 5.0 & 0.32 & $\begin{array}{l}2.5 \times 10^{-} \\
4\end{array}$ & $5.2 \times 10^{-4}$ & $\mathbf{2 . 1 \times 1 0 ^ { - 3 }}$ & $\mathbf{5 . 8 \times 1 0 ^ { - 3 }}$ & $\mathbf{5 . 2 \times 1 0 ^ { - 2 }}$ & $\mathbf{2 . 1 \times 1 0 ^ { - 1 }}$ \\
\hline
\end{tabular}

Table 3b Damköhler numbers calculated using equation 4 for DBU initiator concentrations and flow rates corresponding to VF of DT displacing PEGDA 575 of figure 7 Entries in bold red type are deemed to represent flow close to stability.

\begin{tabular}{|c|c|c|c|c|c|c|c|}
\hline \multicolumn{7}{|c|}{$0.65 \mathrm{~mm}$ gap - Da Approach 2 } \\
\hline DBU & Tau \\
$\begin{array}{c}\text { Conce } \\
\text { ntratio } \\
n\end{array}$ & $\begin{array}{c}\text { Chemic } \\
\text { al (s) } \\
(\mathrm{phr})\end{array}$ & \begin{tabular}{c}
14.34 \\
\cline { 3 - 8 }
\end{tabular} & $\begin{array}{c}10.00 \\
(\mathrm{~mL} / \mathrm{min})\end{array}$ & $\begin{array}{c}5.00 \\
(\mathrm{~mL} / \mathrm{min})\end{array}$ & $\begin{array}{c}3.00 \\
(\mathrm{~mL} / \mathrm{min})\end{array}$ & $\begin{array}{c}1.00 \\
(\mathrm{~mL} / \mathrm{min})\end{array}$ & $\begin{array}{c}0.50 \\
(\mathrm{~mL} / \mathrm{min})\end{array}$ \\
\hline 0 & $\infty$ & 0 & 0 & 0 & 0 & 0 & 0 \\
\hline 0.5 & 3.19 & 0.41 & 0.6 & 1.2 & 2.0 & 5.9 & 11.7 \\
\hline 1.0 & 1.60 & 0.82 & 1.2 & 2.3 & 3.9 & $\mathbf{1 1 . 7}$ & $\mathbf{2 3 . 5}$ \\
\hline 2.5 & 0.64 & 2.0 & 2.9 & 5.9 & 9.8 & $\mathbf{2 9 . 3}$ & $\mathbf{5 8 . 6}$ \\
\hline 5.0 & 0.32 & 4.1 & 5.9 & $\mathbf{1 1 . 7}$ & $\mathbf{1 9 . 5}$ & $\mathbf{5 8 . 6}$ & $\mathbf{1 1 7}$ \\
\hline
\end{tabular}




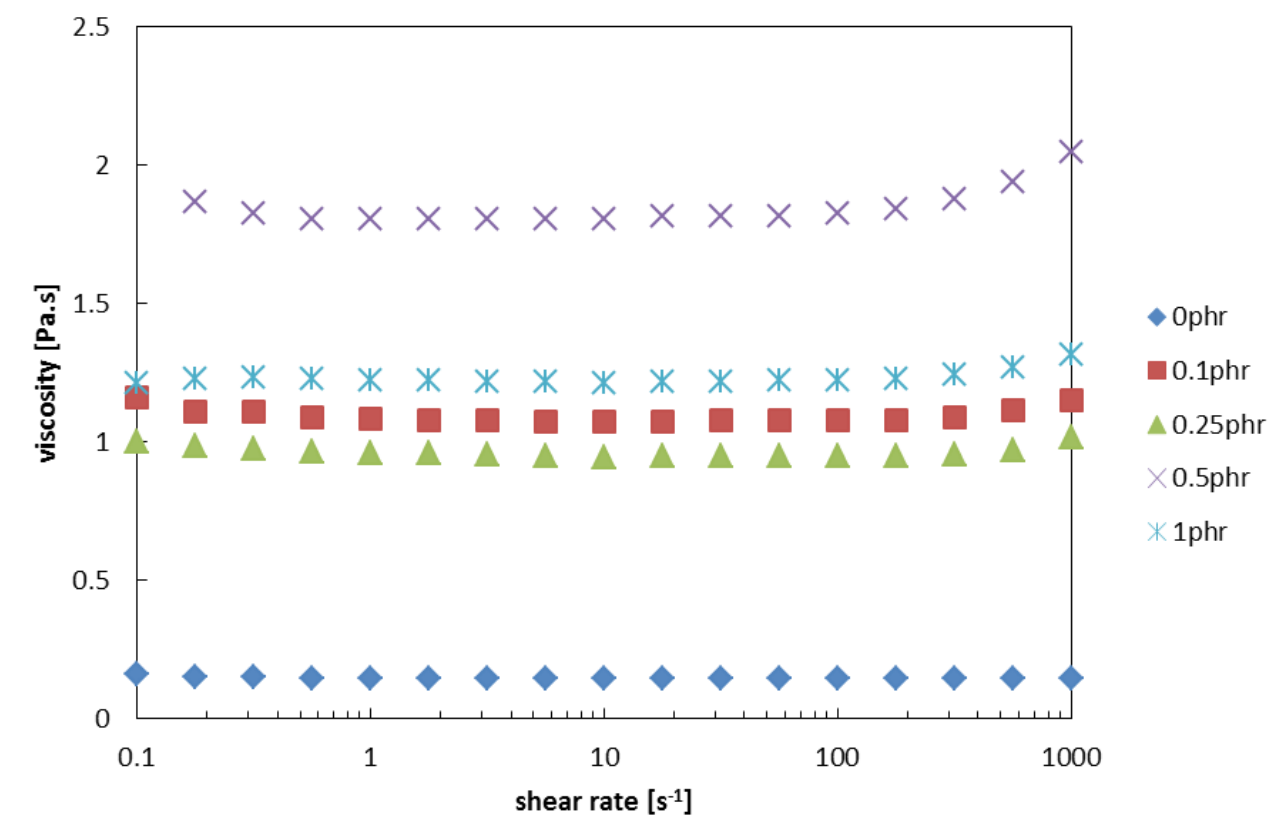

Fig. 8 Viscosity versus shear rate for differing concentrations of initiator. Note that other than a slight variation for 1 phr, the viscosity vs. shear rate is constant, indicative of a Newtonian fluid. 


\section{References}

Al-Housseiny TT, Tsai PA, Stone HA (2012) Control of interfacial instabilities using flow geometry. Nat Phys 8:747-750

Aldushin AP, Matkowsky BJ (1998) Instabilities, Fingering, and the SaffmanTaylor Problem in Filtration Combustion. Combustion Science and Technology 133:293-341 DOI 10.1080/00102209808952038

Almarcha C, Trevelyan PMJ, Riolfo LA, et al. (2010) Active Role of Color Indicators in Buoyancy-Driven Instabilities of Chemical Fronts. Journal of Physical Chemistry Letters 1:752-757

Barati R, Liang J (2014) A Review of Fracturing Fluid Systems Used for Hydraulic Fractring of Oil and Gas Wells. Journal of Applied Polymer Science 40735:1-11 DOI 10.1002/APP.40735

Beeson-Jones TH, Woods AW (2015) On the Selection of Viscosity to Suppress the Saffman-Taylor Instability in a Radially Spreading annulus. Journal of Fluid Mechanics 782:127-143

Berkowitz B (2002) Characterizing flow and transport in fractured geological media: A review. Advances in Water Resources 25:861-884

Borcia R, Bestehorn M (2009) Controlled Pattern Formation in Thin Liquid Layers,. Langmuir 25:1919-1922

Bunton P, Marin D, Stewart E, Meiburg E, De Wit A (2016) Schlieren imaging of viscous fingering in a horizontal Hele-Shaw cell. Experiments in Fluids 57:1-11 DOI 10.1007/s00348-016-2121-0

Bunton PH, Tullier MP, Meiburg E, Pojman JA (2017) The effect of a crosslinking chemical reaction on pattern formation in viscous fingering of miscible fluids in a Hele-Shaw cell. Chaos 27:104514-104511104516

Chan J, Hoyle CE, Lowe AB, Bowman M (2010) Nucleophile-initiated thiolmichael reactions: Effect of Organocatalyst, Thiol, and Ene. Macromolecules 43:6381-6388

Chen C-Y, Liu Y-C (2005) Fingering Instabilities of a Miscible Fluid Annulus on a Rotating Hele-Shaw Cell. Int J Dyn Fluids 1:57-68

Chen CY, Huang CW, Gadelha H, Miranda JA (2008) Radial Viscous Fingering in Miscible Hele-Shaw Flows: A Numerical Study,. Physical Review E 78

Dias E, Parisio F, Miranda J (2010) Suppression of viscous fluid fingering: A piecewise-constant injection process. Phys Rev E 82:067301

Fernandez J, Homsy GM (2003) Viscous fingering with chemical reaction: effet of in-situ produciton of surfactants. J Fluid Mechanics 480:267-281

Fontana J, Dias E, Miranda J (2014) Controlling and minimizing fingering instabilities in non-Newtonian fluids. Physical Review E 89 DOI 10.1103/ PhysRevE.89.013016

Gérard T, De Wit A (2009) Miscible viscous fingering induced by a simple A + $B->$ C chemical reaction. Physical Review E 79

Goyal N, Meiburg E (2006) Miscible displacements in Hele-Shaw cells: twodimensional base states and their linear stabiity. J Fluid Mechanics 558:329-355 
Hejazi SH, Trevelyan PMJ, Azaiez J, De Wit A (2010) Viscous fingering of a miscible reactive $A+B-->C$ interface: a linear stability analysis. J Fluid Mechanics 652:501-528

Homsy GM (1987) Viscous fingering in porous media. Ann Rev Fluid Mech 19:271-311.

Hughes TJ, Honori A, Graham BF, Chauhan AS, Johns ML, May EF (2012) CO2 Sequestration for Enhanced Gas Recovery: New Measurements of Supercritical Co2-Ch4 Dispersion in Porous Media and a Review of Recent Research. International Journal of Greenhouse Gas Control 9:457-468

Jha B, Cueto-Felgueroso L, Juanes R (2011) Fluid Mixing from Viscous Fingering. Physical Review Letters 106:1-4

Jha B, Cueto-Felgueroso L, Juanes R (2013) Synergetic Fluid Mixing from Viscous Fingering and Alternating Injection. Physical Review Letters 111:1-5

John MO, Oliveira RM, Heussler FHC, Meiburg E (2013) Variable density and viscosity, miscible displacements in horizontal Hele-Shaw cells. Part 2. Nonlinear simulations. J Fluid Mechanics 721:295-323

Leewis CM, Mutsaers PHA, de Jong AM, et al. (2004) The mutual diffusion coefficient for (meth)acrylate monomers as determined with a nuclear probe. J Chem Phys 120:1820-1825 DOI 10.1063/1.1635800

Li S, Lowengrub JS, Fontana J, Palffy-Muhoray P (2009) Control of Viscous Fingering Patterns in a Radial Hele-Shaw Cell. Physical Review Letters 102

Loggia D, Rakotomalala N, Salin D, Yortsos YC (1999) The effect of mobility gradients on viscous instabilities in miscible flows in porous media. Physics of Fluids 11:740-742

Manickam O, Homsy GM (1993) Stability of miscible displacements in porous media with nonmonotonic viscosity profiles. Physics of Fluids A 5:13561367

Manickam O, Homsy GM (1994) Simulation of viscous fingering in miscible displacements with nonmonotonic viscosity profiles. Physics of Fluids 6:95-107

Nagatsu Y, De Wit A (2011) Viscous fingering of a miscible reactive A $+B \rightarrow$ $C$ interface for an infinitely fast chemical reaction: Nonlinear simulations. Phys Fluids 23:043103

Nagatsu Y, Hayashi A, Ban M, Kato Y, Tada Y (2008) Spiral pattern in a radial displacement involving a reaction-producing gel. Physical Review $E$ 78:1-6

Nagatsu Y, Iguchi C, Matsuda K, Kato Y, Tada Y (2010) Miscible viscous fingering involving viscosity changes of the displacing fluid by chemical reactions. Physics of Fluids 22:024101-024101 - 024101-024113

Nagatsu Y, Kondo Y, Kato Y, Tada Y (2009) Effects of moderate Damköhler number on msicible viscous fingering involving viscosity decrease due to a chemical reaction. J Fluid Mechanics 625:97-124 DOI $10.1017 /$ S0022112008005429 
Nagatsu Y, Matsuda K, Kato Y, Tada Y (2007) Experimental study on miscible viscous fingering involving viscosity changes induced by variations in chemical species concentrations due to chemical reactions. J Fluid Mechanics 571:475-493

Odian G (2004) Principles of Polymerization. Wiley, New York

Oliveira RM, Meiburg E (2011) Miscible displacements in Hele-Shaw cells: three-dimensional Navier-Stokes simulations. J Fluid Mechanics 687:431-460

Perugini D, Poli G (2005) Viscous fingering during replenishment of felsic magma chambers by continuous inputs of mafic magmas: Field evidence and fuid mechanics experiments. Geology 33:5-8 DOI 10.1130/G1075.1

Podgorski T, Sostarecz MC, Zorman S, Belmonte A (2007) Fingering instabilities of a reactive micellar interface. Physical Review E 76:1-6

Pramanik S, Mishra M (2014) Comparison of Korteweg Stresses Effect on the Fingering Instability of Higher or Less Viscous Miscible Slices: Linear Stability Analysis. Chem Eng Sci 110:144-152

Pramanik S, Mishra M (2015) Effect of Péclet Number on Miscible Rectilinear Displacement in a Hele-Shaw Cell. Physical Review E 91

Riolfo LA, Nagatsu Y, Iwata S, Maes R, Trevelyan PMJ, De Wit A (2012) Experimental evidence of reaction-driven miscible viscous fingering. Phys Rev E 85:015304

Saffman PG, Taylor FRS (1958) The penetration of a fluid into a porous medium or Hele-Shaw cell containing a more viscous liquid. Proceedings of the Royal Society A 245:312-329 DOI 10.1098/rspa.1958.0085

Sarkar SK, Jasnow D (1989) Viscous fingering in an anisotropic Hele-Shaw cell. Physical Review A 39 DOI 10.1103/PhysRevA.39.5299

Shalliker RA, Catchpoole HJ, Dennsi GR, Guiochon G (2007) Visualising viscous fingering in chromatography columns: High viscosity solute plug. Journal of Chromatography A 1142:48-55 DOI 10.1016/j.chroma.2006.09.059

Xu F, Kim J, Lee S (2016) Particle-induced viscous fingering. Journal of NonNewtonian Fluid Mechanics 238:92-99 DOI 10.1016/j.jnnfm.2016.06.014 